\title{
An eye opening experience: A critical turning point in the life of a young woman with a severe visual impairment
}

\section{Nikki Wedgwood}

University of Sydney

\section{Louisa Smith}

University of Sydney

\section{Russell Shuttleworth}

Deakin University

\section{Gwynnyth Llewellyn}

University of Sydney

Abstract
Research on social inclusion often focuses on social exclusion. However, in order to
gain greater insights into ways to facilitate social change, it is equally important to
research the social inclusion of those normally excluded. Indeed, while one important
purpose of studying disabilism is to catalogue and critique all its forms, another
critical purpose is to better understand how disabilism can be resisted and/or
ameliorated at individual and/or societal levels. Thus, it is equally important to
understand when, why and how disabilism does not negatively impact the lives of
people with impairments as well as when it does. This paper presents a single case
study of Lynette, a young woman with a severe visual impairment who has a life-


changing experience in an inclusive environment. In particular, it explores the impact of exclusive and inclusive contexts on Lynette's identity development as she transitions to adulthood. By juxtaposing Lynette's experiences of exclusion with those of inclusion, it highlights contexts in which there is a critical mass of people with impairments living alongside able-bodied people as a possible antecedent/impetus for greater social inclusion of people with impairments in society more generally.

Keywords: Disability, social inclusion, transition to adulthood

\section{Introduction}

Research on social inclusion often focuses on social exclusion. This is understandable given the focus on marginalized groups. However, in order to gain insights into ways to facilitate social change, it is equally important to study instances of the social inclusion of people normally excluded. Indeed, while one important purpose of studying disabilism is to catalogue and critique all its forms, another critical purpose is to better understand how disabilism can be resisted or ameliorated at individual and societal levels. Thus, it is equally important to understand when, why and how disabilism does not negatively impact the lives of people with impairments as well as when it does. Presenting a single case study of Lynette, a young woman with a severe visual impairment, this paper explores the impact of exclusive and inclusive contexts on Lynette's identity development as she transitions to adulthood. By juxtaposing her experiences of exclusion with a life-changing experience in an inclusive environment, it highlights contexts in which there is a critical mass of people with impairments living alongside able-bodied people as a possible antecedent for greater social inclusion of people with impairments in society more generally.

Lynette's case study is drawn from a larger research project-The Transition to Adulthood Study-which uses life history interviews to develop an in-depth understanding of the dynamic relationship between disabilism and the lives of young Australians with a range of impairments. As Connell (1990) has illustrated, "the theorized life history can be a powerful tool for the study of social structures and their 
dynamics as they impinge on (and are reconstituted in) personal life" (p. 84). It thus helps identify how people with impairments, as active, creative human agents, shape their transitional experiences and the extent to which these experiences are shaped by broader social forces, like disability and gender, as well as social institutions like school and family. This helps avoid the common trap of categorizing people with impairments as one homogenous group; 'the disabled'. Whilst providing insights into patterns created by societal responses to particular 'differences' (like impairment), the life history approach is also particularly suited to revealing contradictions and exceptions to cultural norms (Plummer, 2001; Smith, 2010; Wedgwood, 2005). This has made life histories a particularly useful method for 'challenging conventional perceptions' of disability (Atkinson, 2004; Atkinson, Jackson, \& Walmsley, 1997; Atkinson \& Walmsley, 2000). This differs to other qualitative methods because 'most social science in its quest for generalizability imposes order and rationality upon experiences and worlds that are more ambiguous, more problematic and more chaotic in reality' (Plummer, 2001, pp. 39-40).

\section{Method}

Lynette's interview was conducted in her home and lasted almost two and a half hours. The interview was transcribed verbatim then developed into a life history case study. This involved, firstly, organising and condensing the transcript around culturally relevant processes, ideals and institutions in terms of what constitutes an appropriate life history for Australians (e.g. family relations, going to school, working, becoming autonomous), with a particular focus on identity development, social inclusion and transitioning to adulthood. Secondly, another investigator on the research team listened to the interview recording before reading the case study and where her analysis differed, reworked the case study in conjunction with the first reviewer. Lynette was then sent the case study and invited to provide feedback, to ensure the data was not misconstrued. Only minor corrections were made by Lynette and the corrected version is presented here, condensed and reframed with an emphasis on: a) her structural transition to adulthood from school to the workforce and; b) the normative developmental tasks of adolescence and emerging adulthood, such as: peer group membership, sexual inclusion, autonomy from parents and consolidation of identity. The conceptual framework for the study is detailed 
elsewhere (Wedgwood, 2011).

\section{Lynette's Case Study}

\section{Family background/relationships}

Lynette (26) is an incredibly bright, yet humble young woman. She was born with a severe vision impairment and, although she also has hearing difficulties, identifies primarily as vision impaired rather than hearing impaired.

Lynette grew up in the inner city suburbs of an Australian city with her parents and older sister, Margot (28). Lynette's mother, originally from the country, was a secretary for many years, became a stay-at-home mum when her children were young and then, after they grew up, became an artist. Lynette's dad, from a small village in Europe, left school early to take up a laboring apprenticeship, migrated to Australia at 21 'to find a new life' and started his own factory around the time Lynette was born.

Though she has always been close to both parents, Lynette says she is closer to her mum because she stayed at home to look after Lynette and her sister while her dad worked. Though her mother is very supportive, she is not overprotective and fosters independence in Lynette, for example walking with her on new routes until she can do it independently, which Lynette now appreciates:

There was one girl at blind music camp who I shared a room with and she couldn't get dressed on her own because her parents dressed her every morning and it just made me sad for her. It made me realize that my parents, my mum especially, she cared for me in certain ways but she always wanted me to be independent...so I didn't really feel like she was an actual carer...because when I was older I...was doing things on my own. So we went out shopping together but l'd still be choosing things....and when I got dressed every day I chose what I wanted to wear so it was more a motherdaughter relationship like most teenagers would have. Then it was also special in some ways...She had to take me to doctor's appointments and [music] lessons that I couldn't get to myself.

Though Lynette's mum has often advocated for her daughter (like many mothers of children with disabilities), she has also 'always kicked [Lynette] when 
she's taken on the victim attitude.'

As is commonly reported for siblings of children with impairments, Lynette feels her sister Margot misinterpreted and resented the extra attention Lynette received and consequently, their relationship has been fraught from an early age:

She didn't really get along well with me... we used to have a lot of fights. My parents often gave me extra time, especially my dad used to give me extra time with just things I needed extra help with doing...so I think she kind of felt a bit left out and didn't receive as much attention or as much care so I think she kind of resented that a bit and was jealous.

These tensions were heightened by the fact that Lynnette was academically very bright whereas Margot had difficulty with reading and writing. In Year 5, when their parents transferred Margot to a private girls' school, Margot did not want Lynette to go to the same school, which Lynette feels is because:

She found it very difficult to cope with having a blind sister. She didn't accept it very well and for most of our teenage years she didn't want to have me around when her friends were there and she basically didn't want me around at all because she was ashamed of having a blind sister.

\section{High school}

Lynette attended her local mainstream government primary school. Towards the end of primary school she began to feel alone, left out and was sometimes taunted, for example being asked by peers 'how many fingers am I holding up.' When her parents were looking into high school options for Lynette, one private girl's school suggested putting her 'in with all the Down's Syndrome kids.' The selective schools offered to exempt Lynette from sitting an entrance exam but her parents wanted Lynette to be treated like everyone else. They selected Angelica's, a private, middlesized, Anglican girl's school that did everything they could to accommodate and include Lynette. They let her do two subjects accelerated in Year 11 because she excelled in them thus she only had to do four subjects in Year 12. Her math teacher learnt enough Braille to be able to follow Lynette's working out of math problems. The school put all of Lynette's textbooks in Braille, employed someone to attend biology class with Lynette to explain all the diagrams and assist her with 
experiments. Tactile models of the eye and the ear were provided for Lynette to 'look' at. When she excelled in Latin, she was moved to the class in the year above, even though it posed timetabling difficulties: 'they just said...we don't want to hold you back...we don't want to stop you from learning so you can just work a year ahead.'

The only aspect of the curriculum she felt largely excluded from was PE. Though Lynette participated in a lot of sport with her family and competed at an elite level in disability sports outside of school, she was rarely able to participate in PE at school because the curriculum was focused on able-bodied team sports: 'So high school PE I ended up missing out on a lot...I wanted to be part of a team sport and then I took up swimming and kind of felt included. I kind of accepted that team sports were something I couldn't really do.'

Lynette puts the way she was included at Angelica's down to the culture and philosophy of the school: 'The headmistress knew all of the students and just wanted the best for them, not necessarily looking for the best academic results but the best for that student.' Not only was the school 'pretty good on the bullying stuff,' the teachers also encouraged her peers to include Lynette in class, thus:

I felt included in everyday classes because I had friends reading off the board and l'd type it up on my laptop and they used to love that. That included me in the classroom....All my teachers used to include me in groups and stuff.

Lynette recalls the peer groups at school as the smart girls, the good allrounder's, the popular group, the God Squad and the Asian group but noted there 'wasn't really that much rivalry between the groups.' She hung out with everyone but had a lot of friends in the 'God Squad' who were into bible studies. Lynette did not find religion helpful in grappling with the bigger questions in life, like why she was impaired-in fact it 'left more question marks in the end'-but she did bible studies mainly to make friends and to 'fit in.'

Despite the fact that she had friends and therefore was not socially isolated, Lynette reports, like many people with disabilities, that she still felt alone and like 'the odd one out.' For instance, high school and adolescence were the beginning of Lynette's sexual exclusion-she never got asked to dance by boys at school dances. Though she says she 'didn't really mind in some ways because l'd always dance 
with girlfriends' she recalls always feeling disappointed and 'at the end of the night l'd always come home and think, "How come no one ever asked me?" "Why was I left out?"'

\section{Transition out of school}

After having such a personalized and supportive high school experience, transitioning to university was initially very challenging for Lynette. Though her struggles in the first semester to work out 'how the uni was structured' is typical of many first-in-family university students, Lynette had the added challenge of negotiating an institution primarily structured for the education of sighted students. Lynette felt frustrated and hampered by the university's lack of assistance in providing accessible materials:

I didn't get any of the support I was used to. I had to work out how am I going to get the materials in time for class. In my first semester I didn't get them till the end, so my parents were helping me, scanning, putting them into electronic format for me to read....So I didn't have much time.

She also found the environmental 'accommodations' for students with disabilities on campus inadequate. In some places there were no curbs to indicate the end of the footpath and beginning of a road. The Braille signage had inexplicably been put at wheelchair height, thus Lynette was forced to bend down to read them. These experiences contrasted sharply with her experiences later as an exchange student in another university, where the disability services unit was run by a blind man, working with his sighted wife and receptionist with a vision-impairment.

In her first semester at university Lynette also found it difficult to make friends: 'I really struggled...I went from a small high school to this huge campus where I...felt lost in a crowd. The first 6 months I was there, I didn't know anyone really.' By second term, Lynette began to feel less socially isolated. She feels doing a course with small classes rather than enormous lectures helped her: 'that's how I started making friends...you've got to talk to each other. So that helped me make friends.'

\section{Identity and belonging}

Throughout her childhood and teens, Lynette would attend annual camps and other events where she could meet other children with vision impairments. Though she 
would stay in contact with them by phone during the year, she did not see them very often 'so I mainly lived in mainstream society.' Most of her friends and people she saw on a daily basis were sighted. Thus, it is not surprising that:

When I was a teenager I didn't accept it so well, being blind, and I questioned it, all of the things teenagers go through thinking "Why do I have to deal with such-and-such a thing?" and "Why am I the odd one out?" and feeling a bit sorry for themselves and going through all the questions of life. I guess that's part of growing up into an adult.

Thus the task of identity development, which is a major part of the adolescent development phase and which continues and intensifies in the emerging adult phase, took on a different dimension for Lynette because the need to resolve the 'who am I' and 'where do I belong' questions was confounded by her lived experiences of disability and disabilism. Thus, feeling 'different' and like she did not really belong anywhere, Lynette experienced low self-esteem, anxiety and depression during adolescence. This was compounded by poor body image due to both her impairment and her weight:

As a teenager I was quite a chubby kid and then in Year 7 I got diagnosed with [chronic health condition]...I was...quite a chunky kid and got teased a lot about that...that hurt a lot and made me quite self-conscious about how I looked...my sister and my dad [made fun of me]. My sister... was naturally thin...I went through a bit of a bingeing and a bit of a bulimia stage.

As she reached the stage in life where the task of identity development becomes paramount, Lynette felt as though she was unfairly and inadequately faced with the choice of only two identities: blind or sighted. She did not fully relate to either of these: 'I just didn't really know where I belonged...I knew I wasn't really belonging with everyone who was sighted but I also didn't want to be with everyone who's blind.' Thus her identity development was in a state of limbo and Lynette felt frustrated that society would not 'just accept me and let me belong without forcing me into a little box.'

As the 'blind scene' started to become more like a dating scene, Lynette 'felt 
like I needed to be away from the whole scene...I was a bit fed up with all of the issues around being blind.' On the one hand she needed her blind friends 'because of all the issues I had it was great to be able to talk to all of my blind friends and pick their brains about it.' On the other hand, she felt a need to 'readjust to normal life.'

Lynette's identity struggle was resolved when she went abroad for a year during university as an exchange student because she had reached the point in her course where if she wanted to extend herself further she would need to study overseas. Also, 'I think it was good to get away from that whole situation...try to work out where do I fit, where do I belong.' She chose a university recommended to her by a friend because it attracted many blind students from all over that country. Lynette went on a reconnaissance mission with her parents and friend to check out the town and the university:

I was just blown away. Like this whole town... is created basically so blind people can find their way around. Like there is landmarks on every corner...you know the tactile thing on the ground that indicate say where steps are....Like even when we were staying in the youth hostel there was Braille on the wall with a raised map for me to feel. I just fell in love with it.

Lynette made arrangements to be an exchange student there and, after travelling back to the town with her dad, who stayed for two months to help her set her up in an apartment and make sure she knew where to go and so on, she spent another ten months there on her own. By the third month, Lynette was over her home-sickness and started to really enjoy her exchange experience, learning to cook and get herself to university. Thus, in many ways Lynette's exchange experience was typical of many young students moving out on their own or with peersproviding an opportunity to live and develop apart from her parents and to learn to be more independent of her family. For Lynette though, her exchange experience was also a turning-point which helped her to resolve her identity dilemma because it:

Helped me grow up a lot and allowed me to understand a lot more about myself and about my own experiences being blind and being part of a society where...like in Australia there's not many blind people that I know that I come into contact with every single day.... In [the exchange university town]...it was 
a common occurrence there to meet people who were blind...going throughout the city to different places, going to sport, going to university, going to school and so I didn't feel like I was the odd one out anymore and just kind of became accepted. And the citizens of [the town], because there is such a high concentration of blind people, they have sort of become used to how to offer assistance in a way that is not overtly done, but it's more, it's done in a polite, respectful way.

These inclusive experiences were a revelation at a critical time in Lynette's identity development: 'I sort of rediscovered who I was and learned to accept myself a bit.' Until that point Lynette had not felt completely comfortable in either the blind community or in mainstream society. Living in a town which is much more socially and environmentally inclusive of people with vision impairments than the city in which she had grown up, led to the realization that 'the problem' was not her blindness per se but Australian society's response to her impairment. This gave Lynette newfound critical insights and perspectives on how she had been excluded in the past, ultimately changing her emotional response to exclusive experiences in the future:

How does your impairment make you feel?

When? Before I was an adult; frustrated, angry...sad, left out, excluded. Outsider looking in. Now it's part of me. I have grown to be strong. The frustration has gone and it's become more acceptance. The anger has gone, mostly. Like, now I'm not angry about being blind, I do sometimes find it a bit unfair that I have all these health issues. Now I'm more angry when something unjust happens. It's more righteous anger.

In Lynette's case, it was the timing of her student exchange that made the experience so formative because she was having an identity crisis, not uncommon during emerging adulthood, the life phase when most identity exploration and formation occurs (Arnett, 2000). This in turn seemed to resolve her low self-esteem, anxiety and depression. Indeed it is thought that difficulties in constructing a stable identity may have a negative impact on the mental health of young people (Furlong \& Cartmel, 1997, pp. 51-111). 
Furthermore, Lynette believes her liberating experience as an exchange student also gave her the confidence and self-assurance to be in a loving relationship:

I guess what that year abroad did, in realizing that I was part of the crowd and accepting myself, I was more confident when I came home and more selfassured and that started a new process of accepting who I was and I guess being more confident about being blind and more accepting of myself and from there it was easier then to find someone who was going to accept that as well and relate to me as well, whereas before I was trying to accept myself for who I was and not really dealing with it so well and so I guess in some ways that probably related to the relationships I had. When I learned to accept my blindness things started to become a bit easier in some ways.

After finishing her degree in Australia, Lynette returned to the town where she had been on exchange to do further study but discovered that, although she did not experience as much exclusion on the basis of her impairment there, she did not 'belong' there in the same way that she did in Australia where she was born and raised. So, after much uncertainty, she made the difficult choice to return to Australia, where she completed an honours degree, and later, a graduate certificate. Thus, whilst Lynette's identity and self-assuredness as 'a person with a disability' were bolstered and supported in the context where there was a critical mass of other people with vision impairments, being disabled was not the only, nor necessarily always the most critical, aspect of her identity. Being and identifying as Australian was another crucial factor in her levels of inclusion and feelings of belonging.

\section{Love life and sexuality}

Lynette's love life and levels of sexual inclusion have been shaped by disabilism, making it very difficult to find a partner. She has also experienced sexual assault due to her vulnerability as a blind person:

I've also had some sexual experiences which I don't like to remember because they were bad ones because l've attracted the wrong people as well, like I mean, l've had a few people take advantage of me because I haven't 
been able to see, they've done the wrong thing by me.

Until recently Lynette had only had vision-impaired boyfriends, all short-term. Before she met her current boyfriend, Lynette had been on a dating website where she met a few sighted men with whom she went on dates. She found that, even though they knew she was blind beforehand, the way in which some of the men interacted with her showed her that 'if you haven't grown up with someone who's blind or you haven't had that experience then there is a lot to learn about guiding someone around and being confident and just knowing what it's like being blind and the difficulties and challenges that that must present'. Lynette recalled one date with a sighted man who, unfamiliar with leading a blind person, guided her from behind. Later he sent her a message saying 'Nothing against you, but I'm not interested... I don't want you to think it's because of your blindness but l'm just not that interested in you.' Lynette did think it was because of her blindness.

Lynette met her current boyfriend, Tony, at work and they have been together almost two years and are very happy. She now spends half her time at his place and half her time at her mum's. When they are more financially secure, Lynette and Tony plan to buy a house, marry and have two kids. Critical to their relationship is the fact that when Tony was growing up his best friend was blind: 'I could see how he just accepted blind people as normal people rather than not knowing how to deal or... walk with someone who was blind.' Unlike the sighted men from the dating sites:

He already knew what it was like having blind friends and he's had one other blind partner before and he says he enjoys it a lot more than having someone who's sighted which l'm still trying to get my head around in some ways but I mean I can see what he means. I'm more of a tactile person because of my blindness, that's just my way of learning someone and knowing something. He's quite an affectionate guy.

Conversely, Lynette prefers going out with sighted men because:

It's easier to get around with a sighted guy [laughs]...I'm not really one to just stay at home; I'm a very active person. I like... being out and about... I'm a very sociable person, so it makes it easy to get anywhere...because...if I'm struggling I can ask [Tony] to guide me....Whereas with someone blind, I've 
got to either lead them or they've got to lead me or if I'm meeting them somewhere then we've got to meet at an exact location...otherwise you go past one another. I've got friends who are going out with a blind person and they say there are added benefits because you've got the same experiences as the other person so you can relate better in some ways but I also find it quite enjoyable having someone who can tell me that I look good or say, "You've got chocolate on your face, here." Just practical things are so much easier than living with someone who is blind as well.

Having a sighted boyfriend also means being able to go to the movies: 'I've got a really best friend I've been friends with all my life and he'd be the one who when l'd go to the movies he'd be describing everything and now that's [Tony].'

After years of sexual exclusion, having a sighted boyfriend who tells her she is beautiful and sexually desirable has improved Lynette's self-esteem, especially her body image:

Before I went out with him, I was a bit ashamed about being naked in front of someone because I knew they were judging you and looking at you. I guess from all the teasing...I think from the first time we slept together he saw me naked and he was telling me I was beautiful and I was trying to cover up and he said 'I've already seen it all.' It's helped my body image a lot...I feel a lot more comfortable than I used to. Being desired by him, and he constantly gives me good feedback about that, tells me that I'm sexy and that I'm beautiful. That affirmation helps to take the other stuff away. Knowing that he does desire me is a good thing on its own.

\section{Peer and friendships}

Lynette identifies as very gregarious: 'I do like going out and meeting people. I'm very sociable.' She has a lot of friends, both blind and sighted, including a number of close friends from high school with 'similar interests' and four long-term university friends who she sees quite often: 'we have dinner, see a movie, go have a coffee.' Lynette says she is 'slack' with some of her blind friends, mainly using the internet to maintain contact. Her best friend is a sighted man she has known since childhood. She also has friends through her mother. 
Lynette has found that the onus is usually on her to cultivate and maintain friendships and relates this primarily to the fact that she has an impairment:

I'm the one who is ringing up and suggesting to do something or seeing how they're going. That's partly my nature but it's because I know I need to hang onto my friends.... It's part of being impaired. The onus is on me to have those friends...I find that because l've got an impairment l've got to hold onto the people I do know, especially the ones who I'm close to. They are just so important to me. I guess mainly because I'm not swamped by so many other things...I'm quite good at listening to people so I think that's useful sometimes to gather friends.

Having an impairment has also meant having to be aware, even wary, of what it is people want out of a friendship with her: 'I also had to learn who were my real friends and who were just there because they wanted to help or because they wanted to be seen to be friends with a blind person...just having the contact back home [whilst living overseas] made me realize who my real friends were.'

\section{Employment/work/ future aspirations}

Despite her excellent academic credentials and achievements, Lynette has been unable to find work using her university qualifications. Though there are some limitations to the type of work she can do due to her vision and hearing impairments, most of Lynette's exclusion and/or marginalization from the workforce is due to the disabilism and prejudice of potential employers who overlook her abilities due to fear of her disabilities:

There's still a lack of understanding about how someone blind can fit into the workplace or become a good employee. So that still frustrates me. I get excluded from the workplace and from quite a lot of jobs which I think, if they thought a bit differently, I wouldn't be excluded.

Lynette got her current job in a government organization after a visionimpaired friend suggested she apply for a position there because they are inclusive of people with vision impairments. Lynette certainly feels included because, not only 
are there are a number of other vision-impaired employees, but she goes to lunch with a group of workmates every day and says, 'they all look out for me...that's one of the things that makes the work environment nice.' However, her job conducting telephone surveys is an enormous under-utilisation of her educational training, abilities and intellectual potential. Thus, Lynette is 'still trying to explore options about what kind of work l'd like to do.'

\section{Conclusions}

Lynette's case study illuminates the lived experience of inclusion as complex (involving the intersection of social structures like disabilism with personal development phases like adolescence and transitioning to adulthood) and dynamic (changing from one life phase and context to another). Thus life history research can help us to enrich and expand our concept of the "inclusion" of people with impairments beyond simple measures such as education, employment, housing, income and independent living. For instance, Lynette did well at school, has a university education, is employed, has friends and leads her life largely independent of her family, unlike many other young Australians with impairments (Emerson, Honey, \& Llewellyn, 2013). Using these indicators, we could deem Lynette's transition to adulthood successful. Yet, ultimately these factors on their own had little impact on Lynette's levels of sexual, social or workforce inclusion. Those were only achieved in contexts where able-bodied people had become so used to living or working with visually impaired people that they no longer viewed or treated them as 'different' or inferior. Indeed, the only time Lynette did not feel socially excluded on the basis of her impairment was when she lived in a town in which she was just one of thousands of visually impaired people. Similarly, after years of sexual exclusion, Lynette was finally able to develop a healthy sexual relationship with a young man because he had grown up being very close to, and familiar with, a visually impaired person. Moreover, despite having a university degree with honours and a graduate certificate, Lynette has been unable to find work using her qualifications and her current employment is determined primarily by the fact that the organization she works for employs other people with vision impairments and is one of the few she has come across who are willing to make accommodations for her.

Thus, Lynette's life-changing experience as an exchange student suggests 
that a critical mass of people with disabilities leads to social and community environments that are more socially and physically participatory for people with impairments. It therefore seems that the more able-bodied people see and interact with people with impairments on an everyday basis, the more accepting and inclusive they become. Given that roughly half of the 2.2 million Australians with disabilities of working age are unemployed (Australian Government, 2012, p. 38), one way to increase everyday interactions of able-bodied people with people with impairments as work colleagues and/or service providers is to better facilitate the employment of Australians with impairments. As more people with impairments are employed in the workforce, able-bodied colleagues and people more generally will see their abilities, not just their disabilities and will get to know them personally as 'just people', rather than as anonymous 'disabled people.'

Taking into account the importance in Lynette's case of the intersection of her transition to adulthood with her experience of social inclusion, another approach may be to establish one or more universities in Australia which can attract a critical mass of students with disabilities. For Australian students with impairments this would eliminate the extra layer of complexity that Lynette experienced due to her experience of critical mass being in a foreign country where she felt she did not really 'belong'.

Further evidence to support the 'critical mass theory' is the University of California, Berkeley in the United States which, like the university Lynette visited, attracts disabled people from across one country. Moreover, this is where the birth of the Disability Rights Movement occurred, and the city of Berkeley itself has become an exemplary accessible community for disabled people who are viewed by most residents as integral members. Their Disabled Students Program has been particularly influential worldwide in the integration of disabled students into tertiary education and university life. Australia and other countries would do well to look to such models because, as both the Berkeley example and Lynette's case study suggest, social inclusion policies in a university ripple through to the society at large, changing not only the institution itself and the experiences of students with disabilities but also the culture, composition and attitudes of the surrounding community more broadly.

As we analyse the case studies of Lynette and the other 50 or so participants 
in the Transition to Adulthood project, we see disablism playing out in a wide variety of ways in different life circumstances, for instance in the form of denial from family members, sexual exclusion or abuse by peers, bullying by classmates and/or low expectations from teachers or bosses. Many participants experience disabilism in one school but not in another, or at university but not in the workforce (or vice versa). Some experience disabilism at home from their own families while for others home/family is where they feel most included. Some participants reported more exclusion in one life phase than in another (Wedgwood, 2011). Others (like Lynette) experience inclusion in some contexts or parts of her their lives but not in others. Perhaps most importantly, when given the opportunity to talk about their lives, many have stressed their appreciation of the positive outcomes and influences of having an impairment-some even saying that if there were a cure, they would choose to stay as they are. In short, the use of life history case studies helps us to go beyond universalising the experiences of living with an impairment as static and always negative (Campbell, 2008), allowing a much more contextualised and nuanced analysis of everyday experiences of exclusion and inclusion in the lives of people with impairments.

\section{References}

Arnett, J. (2000). Emerging adulthood: A theory of development from the late teens through the twenties. American Psychologist, 55(5), 469-480.

Atkinson, D. (2004). Research and empowerment: Involving people with learning difficulties in oral and life history research. Disability \& Society, 19(7), 691702.

Atkinson, D., Jackson, M., \& Walmsley, J. (1997). Forgotten lives: Exploring the history of learning disability. Kidderminister: BILD Publications.

Atkinson, D., \& Walmsley, J. (2000). Oral history and the history of learning disability. In J. Bornat (Ed.), Oral history, health and welfare (pp. 180-202). London: Routledge.

Australian Government. (2012). Social inclusion in Australia: How Australia is faring $\left(2^{\text {nd }}\right.$ ed.). Canberra: Australian Social Inclusion Board.

Campbell, F. K. (2008). Refusing able(ness): A preliminary conversation about ableism. M/C Journal, 11(3).

Connell, R. (1990). An iron man: The body and some contradictions of hegemonic masculinity. In M. Messner \& D. Sabo (Eds.), Sport, men and the gender order. Critical feminist perspectives (pp. 83-95). Champaign IL: Human Kinetics. 
Emerson, E., Honey, A., \& Llewellyn, G. (2013). Left behind: 2013. Monitoring the social inclusion of young Australians with self reported long term health conditions, impairments or disabilities 2001-2011. Sydney: Centre for Disability Research and Policy.

Furlong, A., \& Cartmel, F. (1997). Young people and social change: Individualization and risk in late modernity. Buckingham: Open University Press.

Plummer, K. (2001). Documents of life 2: An invitation to a critical humanism. London: Sage.

Smith, L. (2010). Mother of all constructions: Mothers in male dominated work. In S. Goodwin \& K. Huppatz (Eds.), The good mother: Contemporary motherhood in Australia (pp. 51-68). Sydney: Sydney University Press.

Wedgwood, N. (2005). Just one of the boys? A life history case study of a male physical education teacher. Gender \& Education, 17(2), 189-201.

Wedgwood, N. (2011). A person with abilities: The transition to adulthood of a young woman with a severe physical impairment. Young - Nordic Journal of Youth Research, 19(4), 435-454.

\section{Biographical Notes}

Dr Nikki Wedgwood is a sociologist whose research interests include disability, gender, sport, embodiment and life history research. Recent research includes the role of sports participation in the lives of young people with physical impairments and the transition of young Australians with disabilities to adulthood.

Dr Louisa Smith is a research associate with the Australian, Family and Disability Studies Research Centre, University of Sydney. Louisa's PhD explored the embodiment and gender contradictions of women working in the male dominated areas of manual trades and IT. In Louisa's current research in the Transition to Adulthood project she is interested in the lives of young people with disability. Louisa's research interests include embodying inequality, gender, disability, work and the life history method.

Professor Gwynnyth Llewellyn is Professor of Family and Disability Studies, Director, Centre for Disability Research and Policy, University of Sydney, http://sydney.edu.au/health-sciences/cdrp/ and Director of the Australian Family and Disability Studies Research Collaboration (AFDSRC) at the Faculty of Health Sciences, http://sydney.edu.au/health sciences/afdsrc/. Recent work addresses the disadvantage experienced by young Australians with disabilities in the face of social policy interventions designed to alleviate the gap in social, economic and participation outcomes, http://sydney.edu.au/health-sciences/cdrp/publications.shtml. 
Dr Russell Shuttleworth is currently a Senior Lecturer in Social Work, School of Health and Social Development, Faculty of Health Sciences, Deakin University. With a background in both medical anthropology and social work, Russell's primary research interests include social aspects of disability, sexuality and disability, masculinity and disability and sexuality and ageing. He employs critical and phenomenological social theories and ethnographic methods in his research. As a social worker, Russell provided counseling to disabled and elderly clients. Involved in the Disability Rights Movement since the mid-1980s, he also worked for many years as a personal assistant for disabled men. 